\title{
Risk assessment practice within primary mental health care: a logics perspective
}

\section{Adam Flintoff}

The Tavistock and Portman NHS Foundation Trust, London

\author{
Adam Flintoff ${ }^{1}$. Ewen Speed ${ }^{2}$. Susan McPherson ${ }^{2}$. \\ ${ }^{1}$ The Tavistock and Portman NHS Foundation Trust \\ ${ }^{2}$ School of Health and Social Care, University of Essex
}

\begin{abstract}
From the 1980s onwards discourses of risk have continued to grow, almost in ubiquity. Ideas and practices of risk and risk aversion have extended to UK mental health care where services are expected to assess and manage risks, and high quality clinical assessment has been revised to incorporate risk assessment. This article problematises practices of risk assessment in mental health provision, focusing on the base rate problem. It presents an analysis of audio recordings of risk assessments completed within a primary care mental health service. The analysis is informed by a critical logics approach which, using ideas from discourse theory as well as Lacanian psychoanalysis, involves developing a set of logics to describe, analyse and explain social phenomena. We characterise the assessments as functioning according to social logics of well-oiled administration and preservation, whereby bureaucratic processes are prioritised, contingency ironed out or ignored and a need to manage potential risks to the service are the dominant operational frames. These logics are considered in terms of their beatific and horrific fantasmatic dimensions, whereby risk assessment is enacted as infallible (beatific) until clients become threats (horrific), creating a range of potential false negatives, false positives and so forth. These processes function to obscure or background problems with risk assessment, by generating practices that favour and offer protection to assessors, at the expense of those being assessed, thus presenting a challenge to the stated aim of risk assessment practice.
\end{abstract}

\section{Keywords}

Risk assessment, base-rate problem, primary care, logics, discourse theory 


\section{Author's biographical notes}

Adam Flintoff is a clinical psychologist. He completed his doctorate in clinical psychology at the University of Essex and this research was completed as part of his doctoral training. He is now working as a clinician within child and adolescent mental health services for the Tavistock and Portman NHS Foundation Trust. He also has an MSc in the History and Theory of Psychology completed at the University of Edinburgh.

Ewen Speed is senior lecturer in medical sociology in the School of Health and Social Care, at the University of Essex. He is interested in health policy in the context of universal service provision and has published widely on this topic, in journals such as Social Science and Medicine, Critical Social Policy and other.

Susan McPherson is a senior lecturer in the School of Health and Social Care at the University of Essex teaching research methods within health professional programmes. Her research areas are within mental health and social care including construction of diagnoses, management and experience of depression, and the impact of trauma. 


\section{Risk assessment practice within primary mental health care: a logics perspective}

From the 1980s onwards discourses of risk have continued to grow, almost in ubiquity. Ideas and practices of risk and risk aversion have extended to UK mental health care where services are expected to assess and manage risks, and high quality clinical assessment has been revised to incorporate risk assessment. This article problematises practices of risk assessment in mental health provision, focusing on the base rate problem. It presents an analysis of audio recordings of risk assessments completed within a primary care mental health service. Using a critical logics approach, the assessments are characterised as functioning according to social logics of well-oiled administration and preservation, whereby bureaucratic processes are prioritised, contingency ironed out or ignored and a need to manage potential risks to the service are the dominant operational frames. These logics are considered in terms of their beatific and horrific fantasmatic dimensions, whereby risk assessment is enacted as infallible (beatific) until clients become threats (horrific), creating a range of potential false negatives, false positives and so forth. These processes function to obscure or background problems with risk assessment, by generating practices that favour and offer protection to assessors, at the expense of those being assessed. This presents a challenge to the stated aim of risk assessment practice, and given the global ubiquity of risk in mental health assessments, this research has international implications for the study of risk and mental health.

\section{Introduction}

Risk has become a familiar contemporary concept, frequently encountered in many areas of twenty-first century life. Risk discourse is now pervasive and seemingly essential, with organisations needing comprehensive risk management strategies and practices to be seen as commercially viable (Power, 2004). Within academic research, risk is a topic frequently studied, and interest in risk and risk assessment as an area of research has proliferated since the 1980s. As one example, Risk Analysis: An International Journal, first released in 1981, published 523 articles in the 1990s and this rose to 2,739 between 2000 and 2009 (Wiley Online Library, n.d.).

Within the area of mental health care, published research varies in scope and intention. Broadly speaking, there is a body of work discussing methods of risk assessment (Buchanan, 1999); risk assessment instruments (Phull, 2012); different theoretical approaches to risk assessment (Doctor, 2004; Holloway, 2004; Witteman, 2004); assessment of different kinds of risk, such as risk of violence (Langan, 2010) and risk of suicide (Cutcliffe and Barker, 2004). There is also work that has explored the practice of risk assessment from the perspective of those involved (Aflague and Ferszt, 2010; Godin, 2004; Moerman, 2012), and approaches using poststructuralist ideas to engage with risk (Crowe \& Carlyle, 2003; Rose, 1998).

Published in Health online 13 April 2018 https://doi.org/10.1177/1363459318769471 
While the research focusing on risk assessment varies widely, it has highlighted some problematic aspects of risk assessment and management, elaborated in the problematisation presented below. Despite this, within mental health provision, service providers are expected to assess, manage and reduce all types of risks, in particular the risk of suicide and violence. This research explores the impact of such risk practices by analysing the quotidian everyday aspect of risk assessment practice within a primary care mental health service. This article adds to the existing literature through an engagement with actual clinical practice as the source of empirical data and through its use of the logics framework and the distinct ontological position this provides.

After outlining the theoretical framework underpinning this paper, we develop a threefold problematisation of risk assessment. This involves considering the ignoble origins of risk assessment through exploring the policy context surrounding its emergence, and considering problems with it, most notably the base-rate problem. Consideration is then given to the consequences of current practices surrounding risk assessment. Drawing upon existing research, the argument we develop is that risk assessment is problematic due to numerous issues including inaccuracy, the selective nature of the risks considered, encouragement of defensive practice, as well as practices that increase stigma and reduce trust.

After presenting the empirical context and material, the article characterises the risk assessment practice studied as functioning according to a logic of well-oiled administration and a logic of preservation. The logic of well-oiled administration involved a bureaucratic focus which privileged obtaining and documenting information with clients fitting around the institutional working of the service. When the logic of preservation was operating, a horrific fantasy of risk assessment being inaccurate came into effect, which corresponded with the false positive and false negative possibilities of assessment. This led to practices which prioritised reducing the risks to practitioners and the service over and above supporting people with risks they face. This contradicts the stated aims of risk assessment within clinical and policy documentation. We draw from a critical logics approach, which requires a degree of theoretical work in setting up and demonstrating the particular problematisation of risk assessment practices that we utilise in this paper.

\section{Research Methodology: A Logics Approach}

\section{Theoretical Context}

This article draws upon a Logics of Critical Explanation framework (Glynos and Howarth, 2007). This framework has its roots in discourse theory, in particular Laclau and Mouffe's (1985) poststructuralist conception of discourse where all actions, social practices and regimes (systems of practices) are seen as discursive in nature to reflect the view that meaning is central to all human practices. The focus in not on establishing

universal or causal laws, or on providing contextualized understandings of actor's

Published in Health online 13 April 2018 https://doi.org/10.1177/1363459318769471 
interpretations. Instead, the focus in on articulating how objects, such as risk assessment practices, acquire an identity through discourses within a given social and historical context, and how this relies upon a contingent articulation of elements to establish a hegemonic discourse.

A series of ontological presuppositions inform the approach, with radical contingency viewed as structuring the entire discursive field. This leads to an inherent instability: 'radical contingency opposes empirical contingency's sense of possibility with a sense of impossibility; the constitutive failure of any objectivity to attain a full identity' (Glynos and Howarth, 2007: 110). There is therefore a radical contingency about the elements, linguistic and material, that constitute the social world, leading to a structural incompleteness in any system. This leads to a focus not on essence or cause, but on contingency and historicity. In terms of risk, this means that for us, risk assessment is not regarded as an intrinsic, essential component of mental health care but one way of doing things with a particular history linked to the projects of certain actors.

The logics approach involves developing a problematisation through archaeological and genealogical work within a discourse theoretical frame. Drawing upon a retroductive mode of reasoning, linking discovery with explanation, it creates an interrelated view of research with three stages: problematising phenomena, retroductive explanation, and persuasion and intervention in a community. Through a process of articulation, it characterises the practices being investigated using the relevant logics, their need for analysis using an archaeology and their political and ideological emergence through genealogy.

Central to this form of critical explanation are social, political and fantasmatic logics. Social logics are the rules or grammar of a practice which enable the purpose, form and content to be seen. They can be thought of as patterned social practices, tied to historical contexts. Political logics show the institution, sedimentation or contestation of these social practices. Fantasmatic logics refer to the ideological grip of a particular practice or regime. The concept of fantasy is used to explain why practices resist or embrace change, with fantasy operating to obscure the radical contingency of the social world and thus promising closure (Glynos, 2001).

As an example, in a health care context, a social logic of choice would instantiate practices that prioritise autonomy and the right to decide for oneself, whereas a social logic of care would prioritise alternative practices such as the doctor-patient relationship or developing knowledge (see Mol, 2008). Understanding the political logics involved in this would require detailed diachronic analysis to see how concepts like choice came about within a healthcare context, for example through tracking the introduction and contestation of market based ideas within health care (see Glynos, Speed and West, 2015). Fantasmatic logics capture the appeal of such practices; in this example one fantasmatic element could be how the market 'promises' to function as a panacea for a range of complex problems within the organisation and delivery of healthcare.

Published in Health online 13 April 2018 https://doi.org/10.1177/1363459318769471 


\section{Problematisation}

\section{Policy Context}

The contemporary importance given to managing risk was underscored by a UK Government 2007 publication of Best Practice in Managing Risk, which emphasised the dual objectives of patient autonomy and public safety, and re-described a good therapeutic relationship to include an 'objective assessment of risk' as well as providing 'sympathetic support' (Department of Health, 2007: 3). We consider the publication of this document as a culmination of risk discourse within healthcare policy, which first appeared in the early 1990s as community care was being instantiated as a policy imperative.

By 1990, the Government had introduced the National Health Service and Community Care Act. In the following years, several high-profile incidents occurred in the community. One particularly high-profile case, which had a direct influence on policy, was the random killing of Jonathan Zito by Christopher Clunis in 1992 at a train station. Clunis, who had a diagnosis of schizophrenia, had been in and out of psychiatric services during the five years preceding this incident. The health secretary, Virginia Bottomley, responded by ordering a review of the law surrounding community care received by psychiatric patients following hospital discharge, arguing not enough mechanisms existed to support 'those most at risk' (The Guardian, 1993: 1). Press coverage grew as Zito's wife, Jayne, called for a public inquiry, opposition politicians called for a suspension of plans to close psychiatric units and a review of community care arrangements and resources, and the British Medical Association and mental health charities argued for additional funding and resources for community care.

The findings of the private inquiry, the Ritchie report, echoed the call of a need for more funding and resources and recommended the establishment of risk registers (Ritchie et al., 1994). These were introduced two months later to support supervised discharge, and provide information on patients at risk of serious violence, suicide, or selfneglect. The decision to place someone on the register was said to rest with the responsible consultant psychiatrist in liaison with the team and to be based on detailed evidence.

Critics described the registers as harmful, colluding with an 'exercise designed to shift accountability and [which] disguises poor psychiatric provision' (O'Connor et al., 1994: 1237). The registers were said to be an attempt to distract people from the crisis of community care, such as the need for more community services, 24-hour crisis centres and supported accommodation (Press Association, 1993). Bottomley (1994) insisted however that the registers would help systematise risk assessment and management processes. Some leading psychiatrists agreed, describing risk registers as 'the glue that will hold together all the components of care for those people who cannot hold them together for themselves, and no longer have a mental hospital to do it for them' (Tyrer

and Kennedy, 1995: 193). Risk assessment became increasingly formalised in subsequent years as health care policy shifted towards processes of clinical governance under the

Published in Health online 13 April 2018 https://doi.org/10.1177/1363459318769471 
New Labour Government (Department of Health, 1998), which made chief executives of NHS Trusts accountable for providing recommended treatments, improving service quality, and obligated to have clear policies specifying risk assessment and management (McPherson et al., 2003).

\section{Risk Assessment Practices}

The increasing significance of risk assessment within policy was in line with a broader cultural expansion of risk discourse. In mental health, debate has mostly focused on methods of assessment, centring on accuracy and prediction. An initial clinical approach involved professionals making judgements following unstructured assessments. This was criticised as being anecdotal, subjective, unreliable, and often based on insufficient information (Monahan, 1981). Clinicians were not felt to possess particular expertise in predicting risk, with knowledge of past violence seen as more accurate (Langan, 2010). These purported failings led to the development of an actuarial approach, which involved the development and application of risk assessment tools to identify static or historical factors statistically associated with an increased risk (i.e. risk factors). While these actuarial approaches were given legitimacy through purported objectivity and scientificity, they suffered from what has been termed the base-rate problem, i.e. the difficulty of predicting a behaviour that occurs rarely within a population studied, like violence or suicide within the general population.

Typically, risk assessment tools are considered in terms of 1) sensitivity, i.e. their ability to correctly identify those at risk, and 2) specificity, i.e. their ability to correctly identify those not at risk (Duggan, 1997). Tests have four categories of response, they can correctly identify those at risk (true positive), or not at risk (true negative), incorrectly identify those at risk as not at risk (false negative), or not at risk as being at risk (false positive). A test with low sensitivity will have a high number of false negatives and a test with low specificity will have a high number of false positives. Positive predictive values refer to the proportion of individuals correctly predicted by a test to be at risk and negative predictive values, the proportion correctly predicted to not be at risk. These values are influenced by the prevalence of the behaviour being studied. Using Duggan's (1997) example, hypothetically in a population of 100, where 10 are violent, a test with $90 \%$ sensitivity and $95 \%$ specificity would give a positive predictive value of $64 \%$ and a negative predictive value of $99 \%$. This would mean 64\% (9 people) of those the test identifies as being violent would be violent (i.e. true positive), and $36 \%$ ( 5 people) identified as being violent would not be violent (i.e. false positives). This test would correctly identify $99 \%$ (85 people) of non-violent people (i.e. true negative) and $1 \%$ (1 person) would be identified as not being a risk when in fact they were (i.e. false negatives).

When the prevalence rate changes to 10 in 1000 people (1\%), the same test would maintain a high negative predictive value of $99 \%$ but the positive predictive value reduces to $13 \%$. This means the test would incorrectly identify 59 people as violent (false positive), and incorrectly identify one violent individual as non-violent (false negative). In this case, the majority (86.8\%) of those the test identified as violent would be false positives. This clearly shows a problem with the application of such tests in cases where

Published in Health online 13 April 2018 https://doi.org/10.1177/1363459318769471 
the behaviour is rare within the population. As Szmukler (2001: 85) puts it: 'even a test with an impossible 0.9 accuracy for both true positives and true negatives will be wrong more than nine times out of ten at a base rate of 1\%'. Another hypothetical example, classifying patients into high or low risk categories, with an optimal risk assessment, shows that 35,000 successful risk management programmes would be required to prevent one homicide by patients with schizophrenia (Large et al., 2011). Discussing this problem elsewhere, Szmukler and Rose (2013: 129) conclude that the sort of events which these assessments are designed to prevent 'are not statistically predictable in a clinically useful way when it comes to an individual patient'.

In response, since the 2000s, a combination of the clinical and actuarial approach, termed structured professional judgement, has been described as the preferred method of assessment, drawing upon a combination of professional knowledge of an individual, clinical experience and empirically validated risk factors (Lamont and Brunero, 2009). However, combining these methods does not solve the base rate problem. The Royal College of Psychiatry (2008: 10) state accurate assessment of risk is "never possible for individual patients...the risks posed by those with mental disorders are much less susceptible to prediction because of the multiplicity of, and complex interrelation of, factors underlying a person's behaviour'. Moving to a structured professional judgement also leaves other issues unresolved such as the difficulty of multiple interacting risk factors, difficulties in acquiring accurate information, and how to incorporate actuarial information and prevent or minimise risk (Langan, 2010).

The inability of assessment to accurately predict risk is simultaneously surprising and unsurprising. It is surprising in the sense that it has such a grip over mental health practices, despite the fundamental impossibility of the task. It is unsurprising from the ontological position of radical contingency taken in this paper, which rejects those efforts to develop assessment that reflect a positivist logic encouraging a focus on refining tools, incremental improvement, and a belief that complete knowledge of the social world is fully realisable. The problems with risk assessment have not been used to reconsider the practice, or reflect on its epistemological assumptions or historical development. Instead, risk assessment has become a routine, taken for granted part of conventional mental health practice. This provides an example of what Verhaeghe (2008: 71) describes as a common solution to an epistemological problem, anticipated by Socrates: 'if epistèmè (knowledge) is unable to found arètè (truth), people fall back on doxa (opinion)'.

In this context, the need for risk assessment is less about its intrinsic properties and more about the social function it serves and the need to demonstrate its utility, as evidenced in its UK development as a response to the Zito case. This justification can also be seen in Maden's (2005: 1) argument for structured professional judgement. He described how confidence in the psychiatric profession was low and that 'once the public and politicians have made violence a major issue, services need to be seen to be taking it seriously. Structured risk assessment is not the whole answer, but it sends the right message'. This brings into view the social role performed by risk assessment in relation to the mental health professions. With the instantiation of community care, and incidents like those involving Clunis, perhaps this social function became more ambiguous and risk assessment was a way of restoring it. The shift towards treating people in the community

Published in Health online 13 April 2018 https://doi.org/10.1177/1363459318769471 
rather than in psychiatric units (a global rather than local UK phenomenon) increased the visibility of the risk patients posed, real or imagined, and it was in this context that risk assessment became strategically useful as a way of enabling risk assessors to take on the role of protecting the public, previously provided by incarceration (Foucault, 2001). Importantly, this also aligned with the dominant policy drive to reduce expenditure.

\section{Marginalised Risks}

Both the quest for the perfect system of assessment and reliance upon convention obscure a range of significant issues linked to risk assessment. Assessment tends to focus on risks people with mental health diagnoses pose which marginalises consideration of other risks like living in inadequate accommodation (Godin, 2004). It constructs individuals as risks who need interventions rather than identifying issues within particular communities, such as those with higher levels of poverty, substance abuse and unemployment (Wand, 2012). It may also obscure risks that come from accessing mental health services which potentially include loss of liberty, forced treatment, or negative experiences (Vassilev and Pilgrim, 2007).

There are also risks that emerge from risk assessment when considered in relation to a cultural emphasis on accountability and litigation. It may encourage defensive practice with patients coming to be regarded as a source of threat. This threat may be constituted as material, reputational or professional, if, for example, the professional is shown to have assessed risk erroneously. This leads to what Power (2004) describes as secondary risk management where professionals manage their own risks rather than the primary task for which they are employed, such as providing a mental health service to a patient.

This creates a new kind of expert, one skilled at managing the risks posed to one's reputation through defensive practice, and, by implication, substituting clinical expertise for administrative accountability. Undrill (2007: 295) identifies this as a response to anxiety about future uncertainty; while anxiety may be tamed through assessment, it may also be displaced onto the assessor and potentially create a situation where 'a patient may be detained because not detaining them produces intolerable anxiety in the staff involved'. Risk assessment then can become a form of insurance for professionals who are encouraged to make decisions 'from the perspective of the need to justify it in some public tribunal in the future' (Rose, 1998: 186). This may in part explain why pro-formas used by services tend to focus on risks professionals may be held accountable for at the expense of other risks (Hawley et al., 2006).

More broadly, such practices may influence trust and stigma. Douglas (1992) describes risk as equivalent to a secular form of sin, and as fulfilling a similar function to practices of confinement within Victorian asylums. It becomes an acceptable form of stigma as high-risk individuals are seen as legitimate moral concerns predicated on the assumption they pose an unacceptable level of danger. This bypasses concerns about discriminating against people with a psychiatric diagnosis, yet maintains an association between mental illness and danger, thus reinforcing stigma and authoritarian practices. This may undermine the necessary context for effective treatment and lead to people not

Published in Health online 13 April 2018 https://doi.org/10.1177/1363459318769471 
wanting to access services due to taking time away from building therapeutic relationships and patients wondering what professionals' priorities are compromising trust (Szmukler and Rose, 2013).

\section{Empirical Material and Analysis}

The empirical material included in this paper were audio recordings of risk assessments completed within an Improving Access to Psychological Therapies (IAPT) service. IAPT was a government initiative launched in 2008 and involved the creation of new psychological therapy services across England to treat depression and anxiety disorders (Department of Health, 2008).

The assessments analysed were duty screening telephone assessments which aimed to assess suitability for the service. They were completed following receipt of an urgent referral. They aimed to clarify the problem, assess the level of risk, discuss previous or current treatment, provide information about the service and decide about appropriate support. They followed a pro-forma and ranged between forty and fifty-five minutes. Service documentation specified a range of criteria for access organised around mental health disorders, and a range of exclusion criteria, one being an assessment of significant levels of risk to self or others within the past three months.

There were nine participants in this research. Six of the participants were people receiving assessments, referred to as clients. They were all aged over 18 , four were male and two, female. Three participants took part in their roles as high intensity cognitive behavioral practitioners. Two practitioners were female and one, male, and the practitioners who completed the duty screening assessments were all considered senior members of clinical staff. The assessments took place in the participating service and were recorded via a digital recorder connected to a telephone. They were collected over a six-month period. A total of eight assessments were recorded with the initial aim being to collect six to eight assessments. Two of the assessments were not used in the analysis due to clients changing their mind about participation following their assessments. As the assessments follow a pro-forma there were similarities across the assessments although the analysis presented here, in line with the approach taken, is not attempting to describe the 'truth' of risk assessment practice but a critical explanation of the material studied in line with a view of the social world as radically contingent. All participants provided written informed consent, and the study obtained ethical approval from an NHS committee and the Research and Development Department of the participating Trust.

The analytical process involved a structured application of the logics framework following the theoretical perspective described. The assessments were transcribed and the analysis involved an iterative process of reading and listening to the assessments before labelling aspects of the empirical material as social, political and fantasmatic logics. Patterns were explored and the logics were reworked throughout the analysis to develop an overall articulation. To identify logics, the focus was on understanding what was taking place within the interaction between participants to characterise the way risk was assessed (social), considering alliances informing the interaction (political) and evidence of beatific and horrific dimensions of fantasy to provide an explanation as to why

Published in Health online 13 April 2018 https://doi.org/10.1177/1363459318769471 
participants invested in the practice (fantasmatic). As political logics require a more diachronic form of analysis which the empirical material did not provide, these were backgrounded here.

\section{Findings}

The empirical material will now be presented as part of an overall critical explanation. This is followed by an elaboration of the social logics that operated within the duty screening assessments and consideration of these social logics in relation to fantasmatic logics.

\section{Empirical Extracts}

Extract 1 provides an example of how a practitioner, Nick (pseudonyms used throughout), explained the assessment format. It shows the emphasis placed upon administrative and bureaucratic process. Nick referred to items from the pro-forma, used to structure the assessments, including completing a 'set questionnaire', 'some other added questions relating to risk' and 'some other questions... relating to other conditions'.

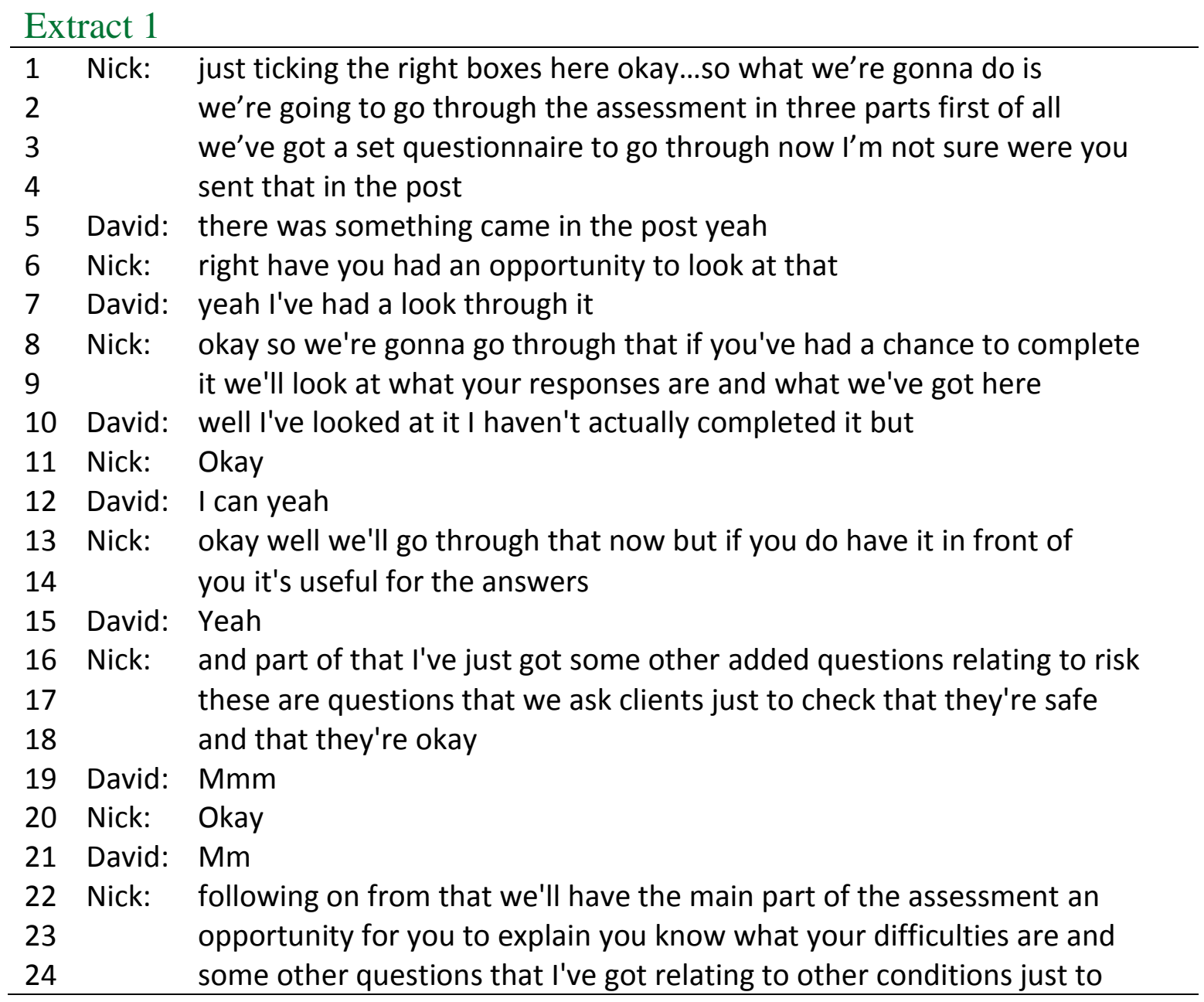




\begin{tabular}{lll}
\hline 25 & & screen those conditions \\
26 & David: & Mmhmm \\
27 & Nick: & and then we'll talk about what options are available based on what \\
28 & & we've discussed \\
\hline
\end{tabular}

While this extract demonstrates how Nick clearly explained or normalised the assessment process, it also highlights the administrative focus. Initially, Nick tests the process has worked as it should (i.e. the postal questionnaire, lines 1-3). This functions to establish that process has been followed. Receipt of the questionnaire then completely determines the shape of the rest of the interaction. In line 13 Nick asserts having the form to hand is useful for the answers, reinforcing by implication a set pattern of response. The accuracy of the instrument will only be enhanced if responses are confined to its predetermined parameters, downplaying the risk of any false results. Risk assessment was here presented as capable of straightforwardly knowing if people are safe and okay, through the structured administration of a questionnaire, speaking to the beatific dimension of fantasmatic logics. It features as a taken-for-granted aspect of mental health practice. This extract also demonstrates how client's explaining their difficulties is said to be the main part of the assessment but is actually subordinated to other aspects, like completing the questionnaire and risk questions. Even when the possibility of extraneous factors outside of the questionnaire are addressed, they are (to be) controlled (screened for) through the use of the instrument (lines 24-25).

\begin{tabular}{lll} 
Extract 2 & \\
\hline 1 & Mary: & [typing] \\
2 & Claire: & you can type quick \\
3 & Mary: & just about \\
4 & Claire: & ha ha ha \\
5 & Mary: & I am getting there when I look through there's a lot of abc corrections \\
\hline
\end{tabular}

Extract 2 demonstrates how recording information that could be utilised for decision-making processes was prioritised over other aspects, such as the client's perspective or experience of the assessment. The importance placed upon documenting information was evident from Mary typing, illustrating the primacy of the administrative rather than therapeutic role, or rather that the therapeutic task was subsumed within the administrative task. The client waiting for Mary to document information shows the risk to practitioners of not obtaining information and thus the need to manage risks to the service. This administrative role could be extended with practitioners becoming technicians asking questions because the pro-forma required it rather than because it was clinically relevant as shown in extract 3.

\begin{tabular}{lll} 
Extract 3 & \\
\hline 1 & Lisa: & so with this assessment we look well I'm gonna go through a few things \\
2 & & now just to rule things in or out okay \\
3 & Alex & $\begin{array}{l}\text { Yeah } \\
4\end{array}$ \\
Lisa & a kind of general screening so some of these questions won't relate to \\
\hline
\end{tabular}

Published in Health online 13 April 2018 https://doi.org/10.1177/1363459318769471 
Lisa demonstrates in extract 3 her predominantly administrative role which could present a challenge to the development of clinical expertise as she became tied to the proforma. The questions were bureaucratic, administrative ones rather than therapeutic ones. Practitioners remained faithful to the pro-forma, completion of which replaced professional judgement and in this sense became infallible.

The structure of the pro-forma and emphasis on obtaining straightforward information positioned clients as rational, knowing subjects who had the information required to complete the pro-forma successfully. It came to be regarded as more reliable than professional judgement and worked to exclude any contingency that may arise from practitioner subjectivity. Client contingency was dealt with in different ways such as being denied from the outset, or by disallowing it (as shown in extract 4). This vignette followed David mentioning having thoughts he would be better off dead.

\begin{tabular}{lll} 
Extract 4 & \\
\hline 1 & Nick: & okay so if I can just ask you some more questions about those types of \\
2 & & Thoughts \\
3 & David: & Mmm \\
4 & Nick: & just to check that you're okay um if you can answer yes or no to these \\
5 & & Ones \\
\hline
\end{tabular}

Nick followed up on these suicidal thoughts asking 'more questions' which indicated this was a potential risk and brings into view the possibility of a failed assessment and the horrific dimension of fantasmatic logics. Nick managed this by asking David to answer with a 'yes or no', which prevented contingency from surfacing. When client's acknowledged issues conceptualised as possible risks to practitioners and to the service, the limitations of assessment became visible. Another way this was managed was by encouraging clients to assist in the administrative decision-making process, as shown in extract 5 .

\begin{tabular}{|c|c|c|}
\hline 1 & Lisa: & Decause this risk is you know a concern what's your sense of that if \\
\hline 2 & & at the end of the assessment we did think about putting you on the \\
\hline 3 & & waiting list for treatment but you had to wait three or four months do \\
\hline 4 & & you feel you would be safe in doing that or do you think you would \\
\hline 5 & & need something sooner \\
\hline $\begin{array}{l}6 \\
7\end{array}$ & Ben: & $\begin{array}{l}\text { I possibly think I'd be I dunno how to answer that I think I would be } \\
\text { okay but I do want something }\end{array}$ \\
\hline
\end{tabular}

This extract presents Ben's risk as a 'concern' and so brings in the uncertainty involved in assessment and thus the shadow of horrific fantasy. Lisa responded by 
inviting Ben to assess his own risk. Here, his problems were made to fit around the service workings as he was asked to consider his safety in relation to waiting lists. This shows the onus being placed on clients to confirm their own safety was one way of responding to the anxiety generated by assessment. The implication seemed to be that if Ben went on record as saying he can wait three or four months, this gives the service licence to wait three or four months for treatment, as if Ben had sanctioned the decision. The context linked to risk issues could also become extraneous information as shown in extract 6.

\begin{tabular}{|c|c|c|}
\hline \multicolumn{3}{|c|}{ Extract 6} \\
\hline $\begin{array}{l}1 \\
2\end{array}$ & Lisa: & $\begin{array}{l}\text { the question we ask everyone is whether you feel you could be a risk to } \\
\text { anybody else at all }\end{array}$ \\
\hline 3 & Ben: & $\mathrm{mmm}$ not at the moment no \\
\hline 4 & Lisa: & no okay \\
\hline 5 & Ben: & well you know not unless certain situations arose but no \\
\hline 6 & Lisa: & okay and then if you feel at risk from anybody at the moment \\
\hline
\end{tabular}

Ben's response to the initial question was to say 'not at the moment no' which was repeated as 'no'. He then qualified this by acknowledging contingency linked to 'certain situations' but Lisa did not enquire further and moved onto the next item. Therapeutically, there would be an expectation that Lisa might follow up on this contingency, but she does not. In this example, we see how this social practice encouraged practitioners to ignore or downplay the possibility of contingency. The assessments also involved some issues being formulated as risks whilst others were not. Extract 7 provides one example.

\begin{tabular}{lll} 
Extract 7 & \\
\hline 1 & Mary: & okay so in terms of your work has your mood had any impact on your \\
2 & & work at all at the moment... \\
3 & Emily: & I've had a few outbursts at the managers for being useless at their job \\
4 & Mary: & at other staff members have you \\
5 & Emily: & yeah well management \\
6 & Mary: & well if they're not doing their jobs properly ha ha \\
7 & Emily: & I know calling them a bunch of useless wankers probably [inaudible] \\
8 & Mary: & I know how that feels ha ha ha \\
9 & Emily: & I think most people do don't they they just don't say it \\
10 & Mary: & that's it exactly exactly so apart from that it actually work isn't too bad \\
11 & & a few incidents that occurred where mainly management not doing \\
12 & & their jobs properly and you've just pretty much told them as it is yeah \\
13 & Emily: & yeah
\end{tabular}

Despite the potential personal issues involved in calling management 'a bunch of useless wankers', this behaviour was not assessed as a risk. Instead, further exploration 
occurred only around issues that potentially pose risks to the service, as conceptualised on the pro-forma (previous suicide attempts, current suicidal ideation, neglect, risk of harm to/from others). Risks to personal security via a loss of employment, stress caused by disciplinary actions at work, or feelings of hostility to figures of authority do not feature in these criteria. This potentially difficult issue was left unexplored and so no more was known about whether Emily was at risk of losing her job or whether her working conditions were linked to her accessing the service. In contrast, the extract below shows the exploration of an issue conceptualised as a risk to the service.

\begin{tabular}{lll} 
Extract 8 & \\
\hline 1 & Lisa: & do you feel you might be a risk to anybody else at all \\
2 & Alex: & no \\
3 & Lisa: & no do you feel at risk from anybody in any way \\
4 & Alex: & no I don't think so \\
5 & Lisa: & okay you mentioned about your wife when she says abusive things \\
6 & & does she ever get physically aggressive towards you \\
7 & Alex: & she has done once yeah \\
\hline
\end{tabular}

Here, the logics involved worked to facilitate further exploration of this issue. Instead of taking Alex's response of 'no I don't think so' at face value, Lisa, drawing upon information obtained earlier in the assessment, enquired further about this possible risk. This shows how standardised questions could generate short responses and a potential difficulty with the language of risk as it can be understood differently by those involved. Practitioners invested most effort in enquiring about the possibility of client suicide, showing their conceptualisation of this as a key risk to the service.

\begin{tabular}{|c|c|c|}
\hline \multicolumn{3}{|c|}{ Extract 9} \\
\hline 1 & Nick: & I just wanna check as well that you have got things like the other \\
\hline 2 & & support numbers that we give out to clients \\
\hline 3 & Frank: & yeah \\
\hline 4 & Nick: & things like the crisis team numbers... have you been given those \\
\hline 5 & Frank: & yes l've got all them \\
\hline 6 & Nick: & and do you keep them on your phone or somewhere safe where you \\
\hline 7 & & can \\
\hline 8 & Frank: & they are logged into me phone \\
\hline 9 & Nick: & ah that's brilliant okay hopefully you've got the main crisis number ... \\
\hline 10 & & which is a sort of seven day a week twenty-four hours a day \\
\hline 11 & Frank: & yes l've got that \\
\hline 12 & Nick: & okay you've got that somewhere I mean it's useful to put it on your \\
\hline 13 & & phone also put it on a card somewhere where you can access it just in \\
\hline 14 & & case you need it or to give it to someone that you can trust that you \\
\hline 15 & & can you know could also have access to support if needed okay \\
\hline 16 & Frank: & yeah \\
\hline 17 & Nick: & okay so we'll continue on with the assessment \\
\hline
\end{tabular}

Published in Health online 13 April 2018 https://doi.org/10.1177/1363459318769471 
This extract shows one way of managing risks was to provide support numbers to clients. It may be that this genuinely helped Frank but it is interesting to note that providing the numbers was prioritised over considering whether he would use them or further exploration of the suicidal thoughts. This suggests that knowing a client has access to these numbers manages any risks to practitioners that may result from a failure in assessment. Another way of managing risks was to obtain assurances from clients they were not at risk as seen in extract 10. This involved Ben who had mentioned self-harming and a previous suicide attempt.

\begin{tabular}{|c|c|c|}
\hline \multicolumn{3}{|c|}{ Extract 10} \\
\hline 1 & Lisa: & okay so if I were to say this is a bit of a strange question to be asked \\
\hline 2 & & but...if I were to say out of ten how likely is it that you might act on \\
\hline 3 & & these thoughts in the near future nought meaning I'm not going to as \\
\hline 4 & & things are \\
\hline 5 & Ben: & Right \\
\hline 6 & Lisa: & you know taking out the equation of serious illness or of wheelchair \\
\hline 7 & Ben: & yeah yeah \\
\hline $\begin{array}{l}8 \\
9\end{array}$ & Lisa: & $\begin{array}{l}\text { and ten being you know imminent would you be scoring on that scale } \\
\text { at the moment }\end{array}$ \\
\hline 10 & Ben: & it would on the acting on the thoughts I'd put it pretty low \\
\hline 11 & Lisa: & yes so would it be zero \\
\hline 12 & Ben: & nought or one yeah \\
\hline
\end{tabular}

Here, along with bracketing contingency, obtaining a numerical rating of likely future action enabled this assessment to progress. It may be that having this information recorded managed the risks to the practitioner. The logics at play led to a focus on obtaining information that could obviate the service and practitioner of any blame should someone confound the assessment. In this case, it could be demonstrated Ben had been assessed but not fully disclosed his level of risk. This could therefore create a problematic incentive to get clients to say the right things as opposed to actually helping with the primary risk issue. From this view, the object of risk assessment becomes avoiding potential damage to the organisation rather than to the client which presents a considerable challenge to the process of supporting people who may be, as in this case, feeling suicidal. It also demonstrates why practitioners may invest in dutifully completing risk assessments as a way of ensuring protection from the service who function in the role of guarantor.

\section{Discussion}

The analysis of these extracts led to the development of two key social logics that operated within the social practice of duty screening assessments in primary care. These were a logic of well-oiled administration and a logic of preservation. These social logics were considered in relation to fantasmatic logics which taken together enables a 
characterisation of the actual practice of risk assessment studied as well as offering insight into why the practice is completed in the way it is despite its problematic aspects.

Fantasmatic logics are concerned with the ways in which particular sets of discursive practices gain a hold upon a particular field, so in this case, how the fantasmatic appeals of risk assessment have come to heavily influence the work of practitioners. Fantasmatic logics consist of beatific and horrific dimensions. Beatific fantasy relates to narratives structured around ideals of complete social harmony or efficiency, whereas horrific fantasy works in the opposite direction, presenting threats that need to be curtailed to prevent catastrophic decline. Applying fantasmatic logics to the base rate problem, and thus the practice of assessing risks, a true positive or true negative assessment capture the beatific aspects where risks and non-risks are correctly and unproblematically identified. False positives and false negatives reflect the horrific dimension, the problem of inaccuracy and the possibility of people being assessed as risks when they are not, or worse, people not being assessed as risks when they actually are. In the context studied, risk assessment was used to ascertain suitability for the service with people presenting with significant risks being deemed unsuitable. So the horrific dimension involved a fear of denying access to someone who needed it through a false positive assessment, or, worse, granting access to someone who goes onto engage in risk behaviours through a false negative assessment.

This perennial problem of accurate assessment and the anxiety generated by the contingency involved was dealt with through practitioners dutifully completing their bureaucratic and administrative tasks, a logic of well-oiled administration. It was also dealt with through prioritising practices that manage risks to the service, a logic of preservation. Here we see the beatific promise of risk assessment, stood against the horrific promise of a false negative. Such is the investment in the process and practice of risk assessment, that adherence to these practices should maximise true positives and true negatives and minimise false negatives and false positives, thus guaranteeing their protection and professional esteem. It is for the possible enjoyment (jouissance) garnered from accurate risk assessment (and the possible horror of inaccurate risk assessment) that the idea of risk assessment as a viable useful solution exerts such a grip within the field.

The two social logics complemented each other and worked to extended risk practices, by making risk a mundane and quotidian feature of assessments. As the previous analysis demonstrated, this idea of risk as a codifier for mental health draws from a very specific reading of these other codifiers. Typically, this constructed the process of risk assessment as straightforward and infallible, ignoring limitations. When the horrific problem of inaccuracy featured, this was dealt with through obtaining mundane assurances from clients they did not present risks or through documenting information that demonstrated this. This meant that an emergent social practice of being able to demonstrate that risk had been assessed took on more significance than consideration of the actual type of risk the client did (or did not) pose and what the most appropriate clinical response to that level of risk might be. This enabled the service to become a guarantor for practitioners in what is potentially a high-risk situation for them due to the potential for professional vilification.

Published in Health online 13 April 2018 https://doi.org/10.1177/1363459318769471 


\section{Implications}

The articulation of the social logics of well-oiled administration and preservation, and the influence of the beatific and horrific dimensions of fantasy, is not a statement on the truth of risk assessment practice but an attempt at making the empirical material intelligible in line with a view of the social world as radically contingent. It should be considered in terms of its ability to provide a valid explanation of risk assessment practice within the context studied. Three implications will now be considered.

\section{Clients disappear in their actuality and become obstacles, potential false negatives or false positives, constituted in terms of the risks they pose}

The logics articulated led to clients being made to fit around service criteria and prioritised administrative process. This marginalised practices that may involve knowing clients in their actuality including the complexity of their lives and pasts. Contextual information became noise, extraneous information discursively closed down. The disappearance of clients aligns with what Castel (1991: 282) refers to as a shift from the clinic of the subject to the epidemiological clinic, which involves a move from a 'concrete relationship with a sick person...[to] a relationship constituted among the different expert assessments which make up the patient's dossier'.

The extended myth of risk assessment's infallibility could lead to clients becoming threats or obstacles to practitioners and the service, making it difficult to support people with risks they face and so contradicts the stated objectives of risk assessment practice. This provides empirical support for Power's (2004) description of secondary risk management where social actors engaged in risk assessment become preoccupied with managing risks that emerge from the process rather than the primary risks they are employed to manage. Recent work by McCabe et al. (2017) provides another example of how risk assessment practices can be enacted in a way that works against its stated aim, through assessor's framing questions in a way that influences the responses provided.

\section{Administrative processes subordinate clinical judgement and generate practices of self-assessment}

The logics worked to reduce the need for analytical judgement on the part of practitioners who could become tied to the pro-forma. This meant practitioners took on a technical role (with clinical aspects marginalised). The emphasis was on recording risk minimisation information, such as the numerical rating of intention to act on suicidal thoughts. Clients were encouraged to share the responsibility for assessing risk through a form of self-assessment. It is tempting to see this as clients being given a greater say over their involvement with mental health services and so, to invert Jewson's (1976) classic phrase, the reappearance of the sick man within medical cosmology. However, this was not the discourse of the 'sick man' as a totality but a fragmented discourse generated by service specification prioritising managing its own risks. Such self-assessment

Published in Health online 13 April 2018 https://doi.org/10.1177/1363459318769471 
encouraged the inscription of risk discourse which becomes part of the canon of mental health service user's discourse (Speed, 2007).

Risk assessment becomes increasingly sedimented and its problematic aspects concealed

The logics outlined work to conceal the base rate problem, assessment proceeds

as if it is an infallible benevolent process capable of accurately identifying risks through a logic of well-oiled administration. The complexities surrounding the historical development of risk assessment practices, its conceptual problems, the policy context, and the moral and political dimensions surrounding risk, such as what constitutes a risk and to whom, remain out of sight, and this issue is not restricted to UK policy and practice. Rather the ubiquity of these particular approaches and models of risk mean that these issues are international in terms of their relevance. When the limitations of assessment were apparent, the logic of preservation encouraged assessors to prioritise managing their own risks to ensure protection from the service, and, in turn, the service was protected through practitioners' dutiful assessments or documented assurances from clients they do not present risks. This creates a context for a potentially erroneous model of risk assessment to endure and even flourish, and the implications for this in an international policy context (and mental health practice context) must be addressed.

\section{Acknowledgements}

We would like to express our gratitude to the NHS Trust and IAPT service who agreed to host this research and to the participants who agreed to take part and so made this study possible. We would also like to thank the anonymous reviewers for their helpful contributions on previous drafts.

\section{Funding statement}

This research was completed as part of the corresponding author's doctorate in clinical psychology programme funded by the NHS East of England Strategic Health Authority, but did not receive a specific grant from any funding agency in the public, commercial, or not-for-profit sectors.

\section{Declaration of conflicting interests}

The authors declare that they have no conflicts of interest. 


\section{References}

Aflague JM and Ferszt GG (2010) Suicide assessment by psychiatric nurses: A phenomenographic study. Issues in Mental Health Nursing 31(4): 248-256.

Bottomley V (1994) Reply from Mrs Bottomley. Psychiatric Bulletin 18(7): 387-388.

Buchanan, A. (1999) Risk and dangerousness. Psychological Medicine 29(2): 465-473.

Castel R (1991) From Dangerousness to Risk. In Burchell G, Gordon C and Miller P (eds) The Foucault effect: Studies in governmentality. Chicago: University of Chicago Press, pp. 281-298.

Crowe M and Carlyle D (2003). Deconstructing risk assessment and management in mental health nursing. Journal of Advanced Nursing 43(1): 19-27.

Cutcliffe JR and Barker P (2004) The nurses' global assessment of suicide risk (NGASR): Developing a tool for clinical practice. Journal of Psychiatric and Mental Health Nursing 11(4): 393-400.

Department of Health (1998) A first class service: Quality in the new NHS. London: Author.

Department of Health (2007) Best practice in managing risk: Principles and evidence for best practice in the assessment and management of risk to self and others in mental health services. London: Author.

Department of Health (2008) IAPT implementation plan: National guidelines for regional delivery. London: Author.

Doctor R (2004) Psychodynamic lessons in risk assessment and management. Advances in Psychiatric Treatment 10(4): 267-276.

Douglas M (1992) Risk and blame: Essays in cultural theory. London: Routledge. 
Duggan G (1997) Introduction. The British Journal of Psychiatry 170(32): 1-3.

Foucault M (2001) Madness and civilization: A history of insanity in the age of reason. Abingdon: Routledge.

Glynos J (2001) The grip of ideology: A Lacanian approach to the theory of ideology. Journal of Political Ideologies 6(2): 191-214.

Glynos J and Howarth D (2007) Logics of critical explanation in social and political theory. London: Routledge.

Glynos J, Speed E and West K (2015) Logics of marginalization in health and social care reform: Integration, choice, and provider-blind provision. Critical Social Policy 35(1): 45-68.

Godin P (2004) 'You don't tick boxes on a form': A study of how community mental health nurses assess and manage risk. Health, Risk \& Society 6(4): 347-360.

Hawley CJ, Littlechild B, Sivakumaran, T et al. (2006) Structure and content of risk assessment proformas in mental healthcare. Journal of Mental Health 15(4): 437448.

Holloway F (2004) Risk: More questions than answers: Invited commentary on psychodynamic methods in risk assessment and management. Advances in Psychiatric Treatment 10(4): 273-274.

Jewson ND (1976) The Disappearance of the Sick-Man from Medical Cosmology, 17701870. Sociology 10: 225-244

Laclau E and Mouffe C (2014) Hegemony and socialist strategy: Towards a radical democratic politics. London: Verso. 
Lamont S and Brunero S (2009) Risk analysis: An integrated approach to the assessment and management of aggression/violence in mental health. Journal of Psychiatric Intensive Care 5(1): 25-32.

Langan J (2010) Challenging assumptions about risk factors and the role of screening for violence risk in the field of mental health. Health, Risk \& Society 12(2): 85-100.

Large MM, Ryan CJ, Singh, SP et al. (2011) The predictive value of risk categorization in schizophrenia. Harvard Review of Psychiatry 19(1): 25-33.

Maden A (2005) Violence risk assessment: The question is not whether but how. Psychiatric Bulletin 29(?): 121-122.

McCabe R, Sterno I, Priebe S et al. (2017) How do healthcare professionals interview patients to assess suicide risk? BMC Psychiatry 17: 122-131.

McPherson S, Richardson P and Leroux P (2003) Clinical effectiveness in psychotherapy and mental health strategies and resources for effective clinical governance. London: Karnac.

Moerman M (2012) Working with suicidal clients: The person-centred counsellor's experience and understanding of risk assessment. Counselling and Psychotherapy Research 12(3): 214-223.

Mol A (2008) The logic of care: Health and the problem of patient choice. London: Routledge.

Monahan J (1981) Predicting violent behavior: An assessment of clinical techniques. Beverly Hills: Sage.

O’Connor S, Parker J, Mumford D et al. (1994) Failure in community care. Supervision register needs rethinking. British Medical Journal 308(6938): 1236-1237. 
Phull JS (2012) A survey of assessment tools for detecting and managing risk. Mental Health Practice 15(8): 31-33.

Power M (2004). The risk management of everything: Rethinking the politics of uncertainty. London: Demos.

Press Association (1993) 'Risk' register for mentally ill in the community. Press Association, 27 December.

Ritchie JH, Dick D and Lingham R (1994) The report of the inquiry into the care and treatment of Christopher Clunis. London: HMSO.

Rose N (1998) Governing risky individuals: The role of psychiatry in new regimes of control. Psychiatry, Psychology and Law 5(2): 177-195.

Speed E (2007) Discourses of consumption or consumed by discourse? A consideration of what 'consumer' means to the service user. Journal of Mental Health 16(3): 307318.

Szmukler G (2001) Violence risk prediction in practice. The British Journal of Psychiatry 178: $84-85$.

Szmukler G and Rose N (2013) Risk assessment in mental health care: Values and costs. Behavioral Sciences \& the Law 31: 125-140.

The Guardian (1993) Killings force care review. The Guardian, 3 July.

The Royal College of Psychiatrists. (2008). Rethinking risk to others in mental health services: Final report of a scoping group. Available at: http://www.rcpsych.ac.uk/files/pdfversion/CR150.pdf (accessed 22 July 2016).

Tyrer P and Kennedy P (1995) Supervision registers: A necessary component of good psychiatric practice. Psychiatric Bulletin 19(4): 193-194. 
Undrill G (2007) The risks of risk assessment. Advances in Psychiatric Treatment 13(4): 291-297.

Vassilev I and Pilgrim D (2007) Risk, trust and the myth of mental health services. Journal of Mental Health 16(3): 347-357.

Verhaeghe P (2008) On being normal and other disorders: A manual for clinical psychodiagnostics. London: Karnac.

Wand T (2012) Investigating the evidence for the effectiveness of risk assessment in mental health care. Issues in Mental Health Nursing 33(1): 2-7.

Witteman C (2004) Violent figures, risky stories: Invited commentary on...psychodynamic methods in risk assessment and management. Advances in Psychiatric Treatment 10(4): 275-276. 